\title{
Miguel Ozorio de Almeida e a vulgarização do saber
}

\section{Miguel Ozorio de Almeida and the vulgarization of knowledge}

\section{Luisa Massarani \\ Centro de Estudos do Museu da Vida/Casa de O swaldo Cruz/Fiocruz lumassa@coc.fiocruz.br}

\section{Ildeu de Castro Moreira}

Instituto de Física e Programa de Pós-Graduação em História das Ciências e das Técnicas e Epistemologia - UFRJ icmoreira@uol.com.br

\begin{abstract}
MASSARANI, L. e MOREIRA, I. de C.: 'Miguel Ozorio de Almeida e a vulgarização do saber'.

História, Ciên cias, Saúde - Manguinhos, vol. 11(2): 501-13, maio-ago. 2004.

Neste artigo, nosso objetivo é resgatar e refletir sobre o papel importante desempenhado por Miguel Ozorio de Almeida no domínio da divulgação científica no Brasil. Este aspecto pouco conhecido de suas atividades não tem recebido a atenção merecida nos estudos da história da ciência no país. Ao longo de sua carreira, o fisiologista fez conferências públicas e publicou vários textos de divulgação, muitos dos quais incluídos nos livros Homens e coisas de ciência, Ensaios, críticas e perfis e A vulgarização do saber. Este último talvez seja a primeira obra brasileira a discutir de forma mais sistemática a prática da divulgação científica, com suas vantagens e limitações. Miguel O zorio escreveu ainda, em 1933, Almas sem abrigo, romance sobre a vida de um matemático no Brasil, e dirigiu com Humberto Mauro, em 1938, o filme educativo Fisiologia geral.
\end{abstract}

PALAVRAS-CHAVE: divulgação científica; história da divulgação científica; ciência e público; ciência e sociedade.

MASSARANI, L. and MOREIRA, I. de C.: 'Miguel Ozorio de Almeida and the vulgarization of knowledge'. História, Ciên cias, Saúde - Manguinhos, vol. 11(2): 501-13, May-Aug. 2004.

The article rediscovers and explores Miguel Ozorio de Almeida's important role in the realm of scientific dissemination in Brazil. This little-known facet of his activities has not received the attention it deserves in studies on the history of science in Brazil. Throughout his career, the physiologist gave public conferences and published a number of educational texts, many of which are included in the books Homens e coisas de ciência; Ensaios, críticas e perfis; and A vulgarização do saber. The latter is perhaps the first Brazilian book offering a more systematic discussion of the practice of scientific dissemination, along with its advantages and limitations. Miguel Ozorio also wrote Almas sem abrigo (1933), a novel about the life of a mathematician in Brazil, and, in collaboration with Humberto Mauro, he directed the educational film Fisiologia Geral (1938).

KEYWORDS: scientific dissemination, history of scientific dissemination, science and the public, science and society. 
${ }^{1}$ Neste texto, usaremos as expressões 'divulgação científica' e 'vulgarização do saber' para designar a disseminação, junto ao público não-

especializado, de informações

relacionadas a temas de ciência. Ressalte-se no entanto que, embora a expressão 'divulgação científica' atenda bem ao que se propõe aqui, sua definição é vista hoje como insuficiente para dar conta da

complexidade das relações envolvidas na difusão dos conhecimentos; há necessidade de serem agregadas ao conceito dimensões outras tais como o papel da audiência nesse processo; a percepção pública da ciência; e as limitações existentes no processo de produção e nos usos do conhecimento, como aquelas relacionadas a riscos, controvérsias e questões éticas, culturais e políticas. Miguel Ozorio de Almeida preferia adotar 'vulgarização do saber', expressão que, juntamente com 'vulgarização científica', era mais usada na década de 1920 e início da década de 1930, quando escreveu os textos citados neste artigo.

\section{Introdução}

A década de 1920 foi marcada, no Rio de Janeiro, por uma intensificação das atividades de divulgação científicaํ (Massarani, 1998; Moreira, Massarani, 2001). Além de maior uso de jornais, revistas e livros como veículos de difusão de idéias e notícias científicas, foram organizadas conferências abertas ao grande público que tiveram repercussão junto à elite ilustrada da cidade. Em 1923 criou-se a primeira rádio brasileira, a Rádio Sociedade (hoje, Rádio MEC), com propósitos educativos e de difusão científica e cultural. Nesse período, as conferências da Associação Brasileira de Educação ( $A B E$ ) atraíam uma audiência interessada em temas de ciência e cultura. Na década de 1930, sob a inspiração de Roquette-Pinto criou-se o Instituto Nacional do Cinema Educativo (INCE), produtor, nos anos que se seguiram, de centenas de filmes educativos e voltados para temas de ciência, arte e cultura.

Esse surto ascendente de atividades de divulgação científica correlaciona-se com o aparecimento anterior de um grupo de intelectuais e cientistas que tinham como propósito a valorização da pesquisa básica - da pesquisa 'pura' ou 'desinteressada', como então se denominava. Eram professores, cientistas, engenheiros, médicos e outros profissionais liberais, ligados em geral às principais instituições científicas e educacionais do Rio de Janeiro. A estratégia para estimular o desenvolvimento da pesquisa científica passava, segundo eles, pelo aprimoramento do sistema educacional, pela criação de faculdades de ciências e letras que possibilitassem a formação dos cientistas 'puros' e pela criação de um ambiente junto ao público e aos governantes favorável à démarche científica. A divulgação científica para o público ilustrado passou a ser um dos instrumentos utilizados com esse propósito. A organização dos cientistas tornouse também uma necessidade importante, como o comprova a criação da Sociedade Brasileira de Ciências (1916), que se transformaria, em 1922, na Academia Brasileira de Ciências (ABC).

Miguel Ozorio de Almeida era um dos elementos atuantes desse grupo, do qual faziam parte também seu irmão Álvaro, Manoel Amoroso Costa, Henrique Morize, Juliano Moreira, Edgard RoquettePinto, Roberto Marinho de Azevedo, Edgard Süssekind de Mendonça, Lélio Gama, Teodoro Ramos, Francisco Venâncio Filho e outros. No que se refere à importância da ciência pura, assim se expressava Miguel Ozorio, no seu discurso de posse como presidente da Academia Brasileira de Ciências, para o biênio 1929-1930:

A Academia foi constituída dentro de moldes severos e profundamente idealistas. Ela tomou para si, como fim principal, o desenvolvimento da Ciência Pura no Brasil. Quis deixar bem patente 
o seu respeito pela Ciência desinteressada e tratou de criar em seu seio uma espécie de culto pelo espírito científico no que ele tem de mais elevado e mais nobre. ... O conhecimento vale por si, independente de sua utilização, e esse valor é bastante grande para que se não meçam os esforços no afã de adquiri-lo. Ela procurou mostrar a beleza e a dignidade da pesquisa científica e como a descoberta de uma lei natural ou a evidenciação de um fenômeno novo é por si só um objetivo, tem uma finalidade própria (Ozorio de Almeida, 1929).

Sobre as dificuldades de tal empreitada, afirmava no mesmo discurso (idem, ibidem): “Essas necessidades, porém, nem sempre encontram um ambiente propício para a sua grande expansão. Aqueles que as possuem em alto grau se sentem, por vezes, um tanto deslocados, e são considerados espíritos à parte, não identificados com o meio e com a época."

Por outro lado, segundo ele (Ozorio de Almeida, 1931, pp. 235-6), a vida moderna estava cada vez mais dependente da ciência e cada vez mais dela impregnada:

Não são só as pessoas cujas profissões reconhecidamente têm uma base científica, como a Medicina ou a Engenharia, que têm interesse em estar mais ou menos em permanente contato com diferentes ciências. Hoje, todas as indústrias, a agricultura e um grande número de outras profissões sofrem uma evolução rápida, devido à introdução dos métodos e processos científicos. A técnica moderna evolui para um estado racional, muito mais preciso e de rendimento muito maior.

Por isso ele valorizava a atividade de divulgação, acreditando que "a difusão científica traria como resultado a familiaridade de todos com as coisas da ciência, e sobretudo uma confiança proveitosa nos métodos científicos, uma consciência esclarecida dos serviços que estes podem prestar" (idem, ibidem, p. 236).

Neste artigo buscamos resgatar este papel significativo desempenhado por Miguel Ozorio, em geral não mencionado pelos historiadores da ciência: o de divulgador da ciência. Ele destacase na história da divulgação científica brasileira por suas conferências, ensaios e livros voltados para temas de ciência e também por ter colocado em debate questões, ainda hoje bastante atuais, relacionadas à prática da divulgação científica. Seu principal texto a este respeito, A vulgarização do saber, permite-nos entender um pouco mais um dos períodos mais férteis da divulgação científica no país, fornecendo-nos um pano de fundo das principais questões filosóficas e conceituais subjacentes à prática relativamente intensa e diversificada que marcou a época em questão. 


\section{Miguel Ozorio e a divulgação cientifica: conferências, ensaios e livros}

No cenário mencionado anteriormente, a divulgação científica tinha um papel importante a desempenhar. Miguel Ozorio, assim como muitos de seu entorno científico e intelectual, adquiriu consciência disso em meio a processo que tinha, na verdade, características internacionais. No pós-Primeira Guerra Mundial, a esperança depositada na ciência, o interesse por ela e, conseqüentemente, o aumento das atividades voltadas para sua difusão ganharam uma grande amplitude especialmente na Europa e nos Estados Unidos. Exemplo claro foi o enorme impacto gerado pelos trabalhos de Einstein e a construção subseqüente, em torno dele, do mito de um cientista genial e quase sobre-humano.

Miguel Ozorio realizou cursos e palestras voltados para a divulgação científica. Nesse sentido, merece destaque sua participação nos ciclos organizados pela Associação Brasileira de Educação (ABE) entre 1926 e 1929. Em muitos casos apoiados pelo Instituto FrancoBrasileiro de Alta Cultura, tais eventos eram semanais e totalizaram cerca de cinquenta por ano, entre cursos, palestras e conferências, possibilitando apresentações de muitos dos cientistas e acadêmicos da época, além de estrangeiros como Marie Curie, Paul Rivet e Paul Langevin. Cobriam assuntos científicos muito variados, com graus diferentes de aprofundamento. Transitavam de temas especializados a exposições destinadas a pessoas leigas e recebiam boa afluência de público, sendo anunciados em jornais cariocas. Conferências feitas por ele nos eventos da ABE foram: 'A regulação nervosa da respiração' (curso que incluiu quatro conferências em 1927) e 'O otimismo de Metchnikoff' (palestra feita em 1928).

Miguel Ozorio defendia a importância de se produzirem no Brasil livros relacionados à ciência, em particular os didáticos. Em 1925, dizia ele:

Uma das primeiras necessidades da literatura científica é o ensino. No Brasil, não existe ainda literatura organizada nesse sentido. Há alguns raros tratados de uma ou outra ciência. Muitas matérias ou mesmo a maioria delas ainda não possuem o seu representante brasileiro. Até aqui os estudos de ciência têm sido feitos com 0 auxílio de livros estrangeiros. Entre estes, têm ocupado o primeiro lugar os livros franceses. A criação de uma literatura brasileira destinada ao uso de nossos estabelecimentos de ensino só teria vantagens. Em primeiro lugar, há de se tomar em consideração as tendências de espírito que são peculiares a cada povo. Muitas dificuldades que são encontradas pelo estudante brasileiro na leitura dos livros europeus provêm dos hábitos próprios de raciocínio, das características de mentalidade que são diferentes e mesmo da própria organização dos estudos que é diversa (Ozorio de Almeida, 1925, p. 179). 
Em sua concepção, "ao lado da literatura didática, poderia ser colocada a literatura de vulgarização, também praticamente não existente entre nós". E enfatizava: "as vantagens de compor uma série de livros que despertem o interesse geral para as coisas científicas são evidentes" (idem, ibidem, p. 180).

Seu primeiro livro neste domínio foi A mentalidade científica no Brasil (1922), na coleção Cultura Contemporânea, dirigida por Afrânio Peixoto, da Livraria Científica Brasileira. Nos anos seguintes escreveu Homense coisas de ciência (1925), A vulgarização do saber (1931) e Ensaios, críticas e perfis (1938), que reúnem no total em torno de sessenta textos, muitos dos quais especificamente de divulgação científica. Boa parte deles originou-se de conferências ou ensaios e resenhas publicados em jornais e revistas da época. Os temas são variados. Uma breve estatística dos artigos por temas gerais, para possibilitar um panorama sobre seus interesses predominantes, acusa a seguinte distribuição: em Homens ecoisas de ciência, ensaios sobre cientistas (4), temas específicos de divulgação (5), discussões gerais sobre ciência (6), conferências sobre formação profissional (2); em A vulgarização do saber, ensaios sobre cientistas (7), temas específicos de divulgação (5), discussões gerais sobre ciência (2); já Ensaios, críticas e perfis trata menos de temas ligados à ciência e abarca, em sua maioria, assuntos gerais relacionados à educação e à vida política, à opinião pública e à cultura (18), discussões gerais sobre ciência (5), ensaios sobre cientistas (7), textos com temas específicos de divulgação (2).

Alguns artigos são particularmente interessantes para a nossa análise. No primeiro desses livros, o texto maior sobre a mentalidade científica no Brasil, publicado em livreto em 1922, analisa as causas das dificuldades locais de se gerar uma cultura científica. Alguns dos artigos da obra dão destaque à ciência pura, mas há outras incursões interessantes como 'A ciência e a arte culinária' e o texto 'A ciência e a língua portuguesa', este último sobre as dificuldades de se estabelecer uma literatura científica na língua própria do país.

No segundo livro, um artigo de destaque é 'As mulheres na ciência', em que se discute um tema em moda na época, no momento em que 0 ingresso das mulheres nas hostes científicas começava a surgir de forma mais intensa. No livro está incluído o discurso que Miguel Ozorio fizera na ABC em homenagem a Marie Curie, durante a vinda desta ao Brasil. Apesar de advogar em favor da presença feminina na ciência, contra muitos que viam nisso um acontecimento infausto já que elas deveriam manter sua feminilidade e, para tanto, restringirse à faina doméstica - , Ozorio pensa que a probabilidade de uma contribuição significativa para a ciência por parte das mulheres é bem menor que a dos homens. Como exceções (muito raras para 
ele) a essa regra, explora em um artigo especial as contribuições da matemática russa Sofia Kowalevsky. Também neste volume a maioria dos artigos se dedica a discutir temas gerais sobre a ciência, a vida de alguns cientistas e determinados conteúdos de divulgação, como a vivissecção e a psicologia dos animais.

No prefácio, Miguel Ozorio (1931, p. 8) faz uma avaliação das expectativas que tivera com o livro anterior: "Q uando timidamente, há quase sete anos, publiquei o Homens e coisas de ciência não esperava encontrar acolhimento muito animador. Parecia-me tentar um gênero mal adaptado às condições de nosso meio. Os fatos vieram mostrar o infundado desses receios." De fato, o primeiro livro já estava então com sua edição esgotada. Ao discutir o título desse segundo livro, afirma que não poderia se chamar Homense coisas de ciência II, porque, "no volume atual, não existem só homens e coisas de ciência. Algumas mulheres foram nele admitidas, à frente delas a extraordinária So phia Kowalevsky" (idem, ibidem, p. 7).

Em Ensaios, críticas e perfis predominam ensaios sobre assuntos mais gerais, escritos entre 1931 e 1938. No 'Prefácio', o autor comenta suas dúvidas de escrever livros como aquele: "Haverá ainda leitores para este gênero de trabalho e, se os houver, estarão estes [textos] à altura deles?" (Ozorio de Almeida, 1938, p. 9). Pouco adiante discorre sobre o conteúdo de seus livros anteriores e daquele que apresentava:

Nos primeiros predominava a preocupação com assuntos mais ou menos diretamente ligados à ciência ou à vida científica, os aspectos gerais da ciência, as questões de métodos de estudo, a vida de alguns grandes sábios, as relações da ciência com a atividade social contemporânea, o seu papel na vida do espírito, todos esses pontos e outros semelhantes formavam o leit-motive dos meus escritos. Tais preocupações não se acham agora inteiramente afastadas. Nem o poderiam ser porque 0 trabalho científico continua a ser o principal e o mais importante de minha atividade. Mas na maioria dos ensaios, a esfera mais estritamente científica foi largamente excedida (idem, ibidem, p. 9).

No mesmo prefácio, reafirma "convicção de que a Humanidade só progride e vive realmente pela vida do espírito, pela solidariedade da inteligência e do sentimento..." (idem, ibidem, p. 12).

$\mathrm{Na}$ introdução a um livro de 1936, em que são descritos seus trabalhos científicos e que constitui uma espécie de autobiografia científica sintética, Miguel Ozorio justifica o uso de parte de seu tempo de pesquisador para escrever textos voltados para um público mais amplo que seu pares. Segundo ele, o que o motivou a publicar numerosos ensaios, estudos e conferências foram as dificuldades encontradas pelo jovens de obter uma orientação firme nas coisas gerais da inteligência, e mais particularmente nas coisas da ciência. 


\section{Um romance científico: Almas sem abrigo}

0 gênero 'romance científico' narrativa romântica entremeada de fatos científicos e personagens ligados à ciência, com grande destaque na Europa do século XIX - basta mencionarmos as obras de Júlio Verne e H. G. Wells - não esteve completamente ausente na literatura brasileira, embora a raridade dos textos com essas características seja evidente. 0 padre Antônio Vieira já produzira um livro de protoficção, com sua História do futuro, de 1718, e não podemos deixar de registrar uma das obras pioneiras de ficção científica no Brasil, escrita por Augusto Emílio Zaluar, em 1875, na esteira de Júlio Verne: 0 doutor Benignus. Antes desta publicou-se, em meados do século XIX, o romance científico Frei Apolônio de Von Martius, naturalista que percorreu o Brasil e a ele esteve ligado durante toda a vida. Nas décadas de 1920/ 30, destaca Causo (2003), começaram a surgir no Brasil obras mais estruturadas no gênero, como A liga dos planetas (1922), de Albino Coutinho; O presidenten egro ou o Choque das raças (1926), de Monteiro Lobato; A filha do inca (1927), de Menotti del Picchia; e A costela de Adão (1932), de Berilo Neves. Desse período, Miguel Ozorio deixou-nos também um interessante e pouco conhecido exemplo de romance científico, Almas sem abrigo (1933), que aborda as vissicitudes de um cientista, no caso um matemático, no Brasil do início do século XX.

A história trata dos dramas pessoais de dois personagens, um matemático e outro jornalista, desde a adolescência até a maturidade. 0 primeiro personagem central torna-se matemático de méritos após estudar na Escola Politécnica do Rio de Janeiro e na Sorbonne, em Paris. Ambientado na antiga capital federal, o romance possivelmente se inspira, sob determinados aspectos, em cientistas da época. Por exemplo, ao descrever as qualidades de Carlos de Toledo para os estudos matemáticos puros, é difícil não perceber, na sua visão da matemática, um reflexo de Amoroso Costa, íntimo amigo de Miguel Ozorio e elogiado por ele em ensaio publicado anteriormente (Ozorio, 1931) e também em um artigo do

${ }^{2}$ A revista Sciencia e Educação foi lançada em fevereiro de 1929 , sob direção de Adalberto Menezes de Oliveira, gerência de J. S. Sardinha e redação de Eduardo de Brito e Cunha. No editorial do primeiro número, fica patente que 0 objetivo da revista era a divulgação científica articulada com a questão educacional. primeiro número da revista Sciencia e Educação, em 1929. ${ }^{2}$ Curiosamente um dos personagens do romance, o matemático e professor da Escola Politécnica, Oscar de Albuquerque, com sua crítica à obra matemática de Augusto Comte, lembra, e não só pelas iniciais de seu nome, o matemático Oto de Alencar.

0 drama do protagonista - embora centrado nas desventuras amorosas no Rio de Janeiro, a que não dá seguimento, e de um outro ainda mais intenso, ocorrido em sua estada em Paris e com fim trágico - retrata também o isolamento de um cientista brasileiro em um meio desfavorável ao trabalho de pesquisa, em particular se comparado à situação francesa. Um toque de melancolia e desilusão 
percorre todo o romance, no qual o matemático não consegue realizar seus sonhos pessoais e profissionais. A trama inicia, significativamente, com o cientista preparando uma conferência para o "auditório mal caracterizado da Sociedade de Cultura Superior", sobre a teoria da relatividade, e refletindo sobre as dificuldades da empreitada: "Inútil se Ihe afigurava o seu esforço, na ânsia de dar uma forma compreensível, elegante, simples, a essa construção abstrata e transcendente pela qual sentia a sua admiração crescer sempre." (Ozorio de Almeida, 1933, p. 5). Carlos de Toledo busca uma analogia entre a dificuldade de aprendizado na matemática e na música: “E pensou que, como a Música, a Matemática é uma linguagem intraduzível; dizer com os recursos vulgares o que só se pode exprimir com o auxílio desses símbolos, simples e maravilhosos, especialmente criados para dados fins..." (idem, ibidem, p. 13).

O utra incursão de Ozorio de Almeida, dessa vez planejada mas não efetivada, no domínio do romance científico foi a tentativa de escrever um livro a seis mãos. Gastão Cruls, autor de um dos livros mais interessantes de ficção científica no Brasil, A Amazônia misteriosa (1925), dedicado a Alvaro Ozorio, fez o seguinte depoimento sobre a origem da idéia para esse romance:

Miguel Ozorio, Afrânio Peixoto e eu, certa vez, durante uma conversa, pensamos em escrever de parceria um romance em que se tentassem experiências fisiológicas in anima nobili. Mas isso nunca passou de simples palestra. Um dia, porém, já bem mais tarde, veio-me a idéia de ligar a esse romance a lenda das amazonas e, desde então, com a aquiescência de meus ex-futuros colaboradores, decidi-me a escrevê-lo sozinho. Estudada a bibliografia que me permitisse criar 0 ambiente em que ia desenvolver a história, pus mãos à obra e em 1925 era o livro editado (Senna, 1996, p. 239).

Note-se que, no romance de Cruls, um dos personagens centrais é um professor alemão, o dr. Jacob Hartmann, que realiza experimentos fisiológicos sobre animais e seres humanos na Amazônia e produz híbridos entre espécies, gêneros, ordens e até entre classes diferentes de animais. Em seus experimentos, utiliza filhos varões das amazonas, que seriam mortos logo ao nascer; e com suas experiências consegue produzir um hominídeo, cruzamento de uma índia com um macaco coatá. Os aspectos éticos de envolvimento do cientista com pesquisas desse tipo são abordados no romance, com um cunho claro de repúdio a esse tipo de prática.

A partir de sua prática profissional como fisiologista, Miguel Ozorio viria também a colaborar, agora sob uma perspectiva educacional mais explícita, com a incipiente produção cinematográfica brasileira voltada para a educação e a difusão da ciência e da cultura. Com Humberto Mauro, no INCE, então capitaneado por seu amigo Roquette-Pinto, dirigiu o documentário educativo Fisiologia geral. 
${ }^{3}$ Neste catálogo 0 nome de Miguel Ozorio de Almeida está escrito de modo incorreto, como Miguel O sório Pereira.

\footnotetext{
${ }^{4}$ Um outro artigo precursor e muito interessante, que discute a atividade de divulgação científica no cenário brasileiro, foi escrito pelo biólogo francês Louis Couty e publicado na Revista Brazileira (Couty, 1879).
}

Trata-se de um filme mudo, em preto-e-branco, $16 \mathrm{~mm}$, com duração de sete minutos, produzido em 1938 (Catálogo Funarte de Filmes, 1996, p. 59). ${ }^{3}$ Devido ao estado de deterioração da cópia desse filme, em depósito na Cinemateca Brasileira, em São Paulo, assim como de muitos outros similares ali existentes, não nos foi possível vê-lo e analisá-lo.

\section{As vantagens e limitações da divulgação científica}

O pioneirismo e a importância do ensaio A vulgarização do saber - publicado no livro de Miguel Ozorio de mesmo título (Ozorio de Almeida, 1931) e possivelmente um dos primeiros escritos no Brasil em que são discutidas vantagens e limitações das atividades de divulgação científica - justificam que apresentemos a seguir alguns de seus trechos, com 0 intuito de expor suas principais idéias sobre 0 tema. ${ }^{4}$

Para Miguel Ozorio, o público em geral tem sua atenção despertada para as coisas do saber e aspira a participar do movimento incessante das idéias e compreender, pelo menos em suas linhas essenciais, as bases dos grandes fatos científicos e a essência das principais leis naturais. Mas, logo de início, algumas questões se colocam:

Essa aspiração é sem dúvida nobilitante. Será ela útil? Poderá ela ser satisfeita? Que resultados advirão de uma cultura popular mais extensa, e, o que é fundamental, até que ponto poderão os homens de ciência corresponder a esse apelo coletivo? Enfim, terá a ciência alguma coisa a ganhar com esse movimento? (idem, ibidem, pp. 229-30)

Lembra que algumas pessoas "não escondem o seu ceticismo e não crêem na possibilidade de reduzir a termos suficientemente elementares os resultados complexos de pesquisas científicas, para a compreensão dos quais é necessária uma longa preparação". Em contraposição, para ele, "ao leigo não interessa, nem é necessário saber a minúcia técnica e sim apenas as grandes linhas essenciais de um conjunto importante de conhecimentos" (idem, ibidem, p. 235). Assim, a vulgarização científica bem conduzida tem, por fim real, mais esclarecer do que instruir minuciosamente sobre este ou aquele ponto em particular.

No entanto, acredita que algumas áreas do conhecimento são mais fáceis de serem divulgadas:

As ciências ... se distinguem umas de outras pelo modo por que elas são estudadas. Se al gumas põem em trabalho as capacidades superiores do raciocínio, e se para abordá-las com proveito é preciso desenvolver ao mais alto grau o poder de abstração, afastando-se ... do senso 
comum, outras não exigem mais do que as qualidades bem equilibradas dos homens médios. Os seus resultados podem muitas vezes ser isolados, expostos de um modo suficientemente claro, em palavras simples de uma linguagem muito próxima da linguagem cotidiana (idem, ibidem, p. 234).

Nesse sentido, dá exemplos que considera de possível compreensão para os não-especialistas:

As ciências naturais apresentam inúmeras questões que estão nesses casos. Mesmo algumas das grandes concepções orientadoras que se encontram na base dessas ciências podem ser explicadas com sucesso a profanos. Todo o mundo compreende em seus pontos essenciais a teoria da evolução ou a natureza microbiana das doenças infecciosas (idem, ibidem, p. 235).

Entre os temas que considera difíceis de serem divulgados ao público não-especializado, Miguel Ozorio (idem, ibidem, p. 235) aponta a relatividade: "A teoria da relatividade exige para ser compreendida a posse de noções muito elevadas de matemática, por vezes mesmo inteiramente fora da cultura clássica dos matemáticos de profissão." Recordem-se aqui as já mencionadas reflexões do matemático Carlos de Toledo, personagem de seu livro Almas sem abrigo.

Nesse sentido, o autor (idem, ibidem, pp. 232-3) busca elucidar as causas subjacentes às dificuldades para a transmissão de informações científicas:

É impossível, quase sempre, apresentar em linguagem profana um raciocínio que só pode ser assimilado com o auxílio de um símbolo próprio. ... A linguagem comum, a que é utilizada para a vida de todos os dias, tem suas raízes profundas no senso comum. A matemática, como a filosofia, recorre a conceitos, dependentes em certos casos, de uma espécie de senso diferente, e que assim não se adaptam às condições precárias da língua habitual. Dá-se aqui ... o que se observa em um grau muito menor com as traduções literárias. A passagem de certas expressões, que correspondem à mentalidade profunda peculiar a um povo, e que representam exatamente o seu modo de sentir, não pode ser feita convenientemente para outras línguas, que se mostram assim deficientes. A tradução em linguagem vulgar de concepções matemáticas encontra diante de si uma dificuldade desse gênero, mas em proporções muito maiores. Ela terá que ser forçosamente incompleta e defeituosa.

Ele recorda que "a utilidade de pôr o grande público a par do movimento científico tem parecido duvidosa a muitos espíritos", sendo que "o receio dos perigos que oferece a 'meia ciência' é uma 
das principais objeções levantadas". Mas insiste: "esses perigos são mais imaginários que reais. Uma instrução popular bem orientada é feita de modo tal que não deixa dúvidas sobre a competência efetiva dos que a adquiriram. Não é difícil instruir sem deixar ilusão sobre os limites desse saber e sobre as possibilidades exatas que ele confere" (idem, ibidem, p. 235).

No que se refere à questão que indica de início - se a ciência tem alguma coisa a ganhar com o movimento de divulgação científica - , de seu ponto de vista a ciência só tem a lucrar com uma vulgarização bem-feita. Para ele, há exemplos na história em que a correlação entre a pesquisa realizada e os benefícios dela decorrentes é clara e imediata. E exemplifica:

Oswaldo Cruz mostrou que o conhecimento das leis científicas exatas sobre a transmissão da febre amarela é indispensável para a exterminação dessa doença. Não Ihe foi difícil obter em seguida meios para um grande instituto de pesquisas sobre patologia experimental. Ninguém discutiu essa utilidade, tão brilhante havia sido a demonstração que, por força das circunstâncias, era essencialmente popular (idem, ibidem, p. 239).

Mas a coisa pode não ser tão simples: "Q uando se trata, porém, de relações menos imediatas entre os progressos científicos e 0 bem de toda a coletividade, as dificuldades crescem" (idem, ibidem, p. 239).

Miguel Ozorio observa, ainda, que a divulgação científica pode ter um papel importante no despertar de novas vocações: "O contato constante com as coisas da ciência aguça a curiosidade e revela tendências que poderiam de outro modo permanecer para sempre ocultas." E traz conseqüências duradouras para a formação de uma cultura científica, porque, ao se manter "constantemente a maioria das inteligências em contato com a ciência, ela virá criar um estado de espírito mais receptível e mais apto a compreender" (idem, ibidem, p. 237).

\section{Considerações finais}

Neste artigo, buscamos resgatar um papel significativo desempenhado por Miguel Ozorio, o de divulgador da ciência, revisitandoo no contexto de sua época. Ele destacou-se na história da divulgação científica brasileira por conferências, ensaios e livros voltados para temas de ciência e também por ser um dos primeiros a colocar em debate questões ainda hoje bastante atuais, relacionadas à prática da divulgação científica.

Seu principal texto de reflexão sobre a divulgação científica, $A$ vulgarização do saber, permite-nos entender um pouco mais esse que foi um dos períodos mais férteis dessa atividade no país, 
fornecendo-nos um pano de fundo das principais questões filosóficas e conceituais que estavam por trás da prática relativamente intensa e diversificada que marcou as duas décadas em questão. No texto, Miguel O zorio discute dilemas, vantagens e limitações da divulgação científica. Destaca que as limitações e vínculos da ciência não devem ser deixados de lado na busca do entendimento real de seu funcionamento. Entre as vantagens que elenca encontra-se a de despertar vocações científicas entre os jovens, em um momento em que a afirmação e o crescimento da incipiente comunidade científica no Brasil era uma questão candente para o seu círculo de atuação.

Ele acreditava também que o público demonstrava interesse e poderia dominar, de forma genérica, as grandes linhas do pensamento científico. Distinguia, no entanto, áreas das ciências sobre as quais era mais fácil a compreensão geral - como o amplo domínio da história natural - de outras de absorção mais difícil, cujas abstração e matematização elevadas criariam impedimentos profundos. Encarava como desafios maiores, e talvez insuperáveis, para um entendimento mais amplo teorias que na época eram consideradas símbolos do hermetismo, como a relatividade de Einstein. Oito décadas depois, embora as grandes questões por ele colocadas para a divulgação científica ainda permaneçam, podemos perceber que, muito destituída da aura de dificuldade extrao rdinária que adquiriu na época, a relatividade é hoje tema freqüente de divulgação. Por outro lado, sua afirmação de que a probabilidade de uma contribuição significativa para a ciência por parte das mulheres seria bem menor que a dos homens soa hoje despropositada e politicamente incorreta. Tudo isto nos ajuda a perceber que a divulgação científica, ao longo do tempo, responde a motivações e interesses diversificados. Mesmo mantendo algumas questões centrais como themata permanentes, ela varia em função de pressupostos filosóficos sobre a ciência, de interesses políticos e econômicos, dos conteúdos científicos envolvidos, da cultura subjacente e dos meios disponíveis nas diversas épocas e lugares (Moreira e Massarani, 2002).

Concluamos este artigo com uma palavra final de Miguel Ozorio, que deveria ser lida e absorvida ainda hoje por educadores e comunicadores de ciência dotados de visões estreitas sobre seu próprio fazer. Para ele, a divulgação científica "se destina mais a preparar uma mentalidade coletiva, do que realmente a difundir conhecimentos isolados". 


\section{REFERÊNCIAS BIBLIOGRÁFICAS}

Causo, Roberto de Sousa 2003

Catálogo Funarte de Filmes

1996

Couty, Louis

1879

Massarani, Luisa 1998

Moreira, Ildeu de

Castro e Massarani, Luisa

2002

Moreira, Ildeu de

Castro e Massarani,

Luisa

fev. 2001

Ozorio de Almeida, Miguel

1938

Ozorio de Almeida, Miguel

1936

Ozorio de Almeida, Miguel

1933

Ozorio de Almeida, Miguel

1931

Ozorio de Almeida, Miguel

1929

Ozorio de Almeida, Miguel

1925

Ozorio de Almeida, Miguel

1922

Salgado, Alvaro

1946

Senna, Homero

1996

Serrano, Jonathas e

Serrano Filho, Francisco 1930
Ficção científica, fantasia e horror no Brasil (1875 a 1950).

Belo Horizonte, Editora da UFMG.

Rio de Janeiro, Funarte/ Ministério da Cultura.

'Os estudos experimentais no Brasil'.

Revista Brazileira, tomo II, pp. 215-39.

A divulgação científica no Rio de Janeiro: algumas reflexões sobre a década de 20. Dissertação de mestrado em ciência da informação, Universidade Federal do Rio de Janeiro/IBICT-ECO, Rio de Janeiro. (mimeo.)

'Aspectos históricos da divulgação científica no Brasil'. Em Luisa Massarani, Ildeu Moreira, Fátima Brito. Ciência e público: caminhos da divulgação científica no Brasil. Rio de Janeiro, Casa da Ciência/UFRJ.

'A divulgação científica no Rio de Janeiro: algumas reflexões sobre a década de 1920'. História, Ciências, Saúde - Manguinhos, vol. VII(3), pp. 627-51.

Ensaios, críticas e perfis.

Rio de Janeiro, F. Briguiet e Cia.

Breve notícia sobre os trabalhos científicos do prof. Miguel Ozorio de Almeida. Rio de Janeiro, s. ed.

Almas sem abrigo.

Rio de Janeiro, Ariel Editora Ltda.

A vulgarização do saber.

Rio de Janeiro, Ariel Editora Ltda.

Discurso de posse [na Academia Brasileira de Ciências]. Disponível na

internet em www.abc.org.br/historia/m_ozorio1.html. Acessado em 14.9.2003.

Homens e coisas de ciência.

São Paulo, Editora Monteiro Lobato.

A mentalidade científica no Brasil.

Rio de Janeiro, Livraria Científica Brasileira.

A radiodifusão educativa no Brasil. Rio de Janeiro, Ministério da Educação e Saúde/Serviço de Documentação.

República das letras.

Rio de Janeiro, Civilização Brasileira.

Cinema e educação.

São Paulo, Comp. Melhoramentos de São Paulo. 